\title{
Mathematical Modelling of Catalytic Fixed-Bed Reactor for Carbon Dioxide Reforming of Methane over $\mathrm{Rh} / \mathrm{Al}_{2} \mathrm{O}_{3}$ Catalyst
}

\author{
Nor Aishah Saidina Amin ${ }^{1}$, Istadi ${ }^{*}$, and New Pei Yee ${ }^{1}$ \\ 1) Chemical Reaction Engineering Group (CREG), Faculty of Chemical and Natural \\ Resources Engineering, Universiti Teknologi Malaysia, 81310 Skudai, Johor Bahru, Malaysia \\ 2) Department of Chemical Engineering, Diponegoro University, Jl. Prof. Sudharto, Kampus \\ UNDIP Tembalang, Semarang, Indonesia 50239
}

Received: 20 August 2008; Accepted: 25 September 2008

\begin{abstract}
A one-dimensional mathematical model was developed to simulate the performance of catalytic fixed bed reactor for carbon dioxide reforming of methane over $\mathrm{Rh} / \mathrm{Al}_{2} \mathrm{O}_{3}$ catalyst at atmospheric pressure. The reactions involved in the system are carbon dioxide reforming of methane (CORM) and reverse water gas shift reaction (RWGS). The profiles of $\mathrm{CH}_{4}$ and $\mathrm{CO}_{2}$ conversions, $\mathrm{CO}$ and $\mathrm{H}_{2}$ yields, molar flow rate and mole fraction of all species as well as reactor temperature along the axial bed of catalyst were simulated. In addition, the effects of different reactor temperature on the reactor performance were also studied. The models can also be applied to analyze the performances of lab-scale micro reactor as well as pilot-plant scale reactor with certain modifications and model verification with experimental data. () 2008 CREC UNDIP. All rights reserved.
\end{abstract}

Keywords: fixed-bed; mass and energy balances; CORM; RWGS; simulation; $\mathrm{Rh} / \mathrm{Al}_{2} \mathrm{O}_{3}$

\section{Introduction}

The conversion of methane to useful chemicals has gained much attention in recent years with many methods and techniques have been reported [1]. At present, the investigation about indirect transformation of methane via synthesis gas over the novel and promising catalysts is still conducted in search for the most competitive process. Generally, the synthesis gas is produced by steam reforming known as the most economical route for the production of hydrogen and synthesis gas from natural gas. In the carbon dioxide reforming of methane (CORM) reaction, it is desired the conversion of methane and carbon dioxide approach its equilibrium over a suitable catalyst. The catalyst must have sufficient catalytic activity, be resistant to carbon formation and have high mechanical strength as well as be in a suitable shape. The transport resistance can also limit the catalyst effectiveness factor to values much less than unity as only a thin layer of the catalyst surface takes part in the reaction. The effectiveness factor may be influenced by the particle size and porosity of the catalysts as well as their pore diffusivities.

Mathematical modelling technique is the mathematical tools normally used to optimize and analyze a process. Moreover, modelling can also be used to optimize the operating parameters in the scale-up process prior to experimental testing.

* Corresponding Author.

E-mail address: istadi@undip.ac.id (Istadi) 
Such empirical models have already been used to study the production of syngas from natural gas [2]. The detailed mechanistic models are used much more often than empirical models for interpretation of catalytic processes. The mechanistic models are used as a basis for investigation of reaction mechanisms, for the estimation of adsorption and activation energies and for the evaluation of the mass and heat transfer rate constants in the reactor. Furthermore, the mathematical modelling and simulation can also been used to profile the fluid dynamic within the packed bed reactor. The fluid dynamic over a catalyst bed can be used to identify the hot spot phenomenon especially for high exothermic reactions. Process optimization can be accomplished after the kinetic, mass transfer and heat transfer mechanisms are determined and the model parameters are estimated.

Many researchers have utilized mathematical models for analyzing membrane reactors. The one-dimensional mathematical modelling of methane reforming reaction with $\mathrm{CO}_{2}$ in hydrogen selective membrane reactors have been conducted over $\mathrm{Rh} / \mathrm{Al}_{2} \mathrm{O}_{3}$ catalyst [3]. A one-dimensional mathematical modelling of fixed bed reactor for methane steam reforming to produce syngas has also been developed involving detailed intrinsic kinetics studies and those of carbon deposition and gasification [4]. The internal diffusion limitations are also accounted for inside the mathematical modelling. The simulation has also been successfully utilized to analyze the performance of industrial steam reformer process. As a design parameter, the catalyst shape has also affected the safe and efficient operation of methane-steam reforming reactors [5]. The kinetic studies of CORM have also been conducted to determine the intrinsic rate kinetics of CORM and RWGS reactions over $\mathrm{Ni} / \mathrm{La}_{2} \mathrm{O}_{3}$ catalyst [6].

In this paper, the modelling of a lab scale fixed-bed reactor for CORM over $\mathrm{Rh} / \mathrm{Al}_{2} \mathrm{O}_{3}$ catalyst has been studied based on the kinetic parameters. A review of the earlier work indicated only a few literatures are available on the simulation of CORM process over fixed-bed reactors. Among the few papers on the modelling of CORM process are $\mathrm{H}_{2}$ permselective membrane reactor [3] and comparison of an empirical and phenomenological model for the fixed bed reactor [2]. It is suggested that the mechanistic model is used much more than the empirical model to investigate the kinetic studies of catalytic reaction [2]. Majority of the research activities on the modelling of syngas production were concerned on the steam reforming process which has already been commercialized $[4,5]$. The modelling work pre- sented in this paper is to simulate the reactor performances prior to conducting experimental works and to investigate the reactor behaviours which cannot be obtained experimentally. The heat transfer model involving radiation and convection from the furnace has been coupled with a chemical reaction model to predict the thermal behaviour of carbon dioxide reforming of methane and its influence to the reactor performances.

\section{Mathematical Models of Catalytic Fixed-Bed Reactor}

The CORM reaction produces synthesis gas, an industrially important feedstock, is shown in Equation (1) as the main reaction. This reaction is of importance as the two reactants are the major contributors to the greenhouse gas.

$$
H_{2}+\mathrm{CO}_{2} \Leftrightarrow \mathrm{CO}+\mathrm{H}_{2} \mathrm{O} \mathrm{r}{ }_{2} \Delta \mathrm{H}_{298}^{\mathrm{o}}=+41 \mathrm{~kJ} \mathrm{~mol}^{1}
$$

$$
\mathrm{CH}_{4}+\mathrm{CO}_{2} \Leftrightarrow 2 \mathrm{CO}+2 \mathrm{H}_{2} \mathrm{r}_{1} \Delta \mathrm{H}_{298}^{\mathrm{o}}=+247 \mathrm{~kJ} \mathrm{~mol}^{-1}
$$

The side reaction possibly occurred is the reverse water gas shift reaction (RWGS) as written in Equation (2). The symbols of $r_{1}$ and $r_{2}$ denote the net intrinsic rate of carbon dioxide reforming of methane and RWGS reactions, respectively.

\section{Conservation of Mass}

The reactor configuration studied in this work is depicted schematically in Figure 1. The total reactor configuration is shown in Figure 1(a), while the catalyst bed of the reactor section to be studied is in Figure 1(b). Figure 1(c) provides the control volume of reactor bed to be used for model building. A number of acceptable assumptions were made in order to simplify the complex and coupled phenomena of heat and mass transfers and reaction into a mathematical model. These assumptions provide a tractable model without sacrificing accuracy. The major assumptions are: steady state operation, plug-flow behaviour, isobaric conditions ( 1 bar), negligible radial and intra particle gradients, $\Delta \mathrm{H}^{\circ}$ independent of temperature and distributed heat source along the axial bed of catalyst.

A one-dimensional heterogeneous mathematical model of reactor is developed in this work for CORM reaction [7]. The mathematical model is based on the control volume of the reactor bed as depicted in Figure 1. The continuity equations for 
$\mathrm{CH}_{4}$ and $\mathrm{CO}_{2}$ components are shown in Equations (3) and (4):

$$
\begin{aligned}
\frac{\mathrm{dx}_{\mathrm{CH}_{4}}}{\mathrm{dz}} & =\frac{\Omega \rho_{\mathrm{b}} \eta_{\mathrm{CH}_{4}} \mathrm{R}_{\mathrm{CH}_{4}}}{\mathrm{~F}_{\mathrm{CO}_{2}}^{\mathrm{o}}} \\
\frac{\mathrm{dx}_{\mathrm{CO}_{2}}}{\mathrm{dz}} & =\frac{\Omega \rho_{\mathrm{b}} \eta_{\mathrm{CO}_{2}} \mathrm{R}_{\mathrm{CO}_{2}}}{\mathrm{~F}_{\mathrm{CO}_{2}}^{\mathrm{o}}}
\end{aligned}
$$

The rates of disappearance of $\mathrm{CH}_{4}$ and $\mathrm{CO}_{2}$ according to both reactions are written as Eqs (5) and (6):

$$
\begin{aligned}
& \mathrm{R}_{\mathrm{CH}_{4}}=\mathrm{r}_{1} \\
& \mathrm{R}_{\mathrm{CO}_{2}}=\mathrm{r}_{1}+\mathrm{r}_{2}
\end{aligned}
$$

The kinetic studies were conducted over the $\mathrm{Rh} / \mathrm{Al}_{2} \mathrm{O}_{3}$ catalyst, resulting in the net rate of CORM and RWGS reactions as the following equations, respectively [3]:

$$
\mathrm{r}_{1}=\mathrm{k}_{1}\left[\frac{\mathrm{K}_{\mathrm{CO}_{2}} \mathrm{~K}_{\mathrm{CH}_{4}} \mathrm{P}_{\mathrm{CO}_{2}} \mathrm{P}_{\mathrm{CH}_{4}}}{\left(1+\mathrm{K}_{\mathrm{CO}_{2}} \mathrm{P}_{\mathrm{CO}_{2}}+\mathrm{K}_{\mathrm{CH}_{4}} \mathrm{P}_{\mathrm{CH}_{4}}\right)^{2}}\right]\left[1-\frac{\mathrm{P}_{\mathrm{CO}} \mathrm{P}_{\mathrm{H}_{2}}}{\mathrm{~K}_{1} \mathrm{P}_{\mathrm{CH}_{4}} \mathrm{P}_{\mathrm{CO}_{2}}}\right]
$$

$$
\mathrm{r}_{2}=\mathrm{k}_{2} \mathrm{P}_{\mathrm{CO}_{2}}\left[1-\frac{\mathrm{P}_{\mathrm{CO}} \mathrm{P}_{\mathrm{H}_{2} \mathrm{O}}}{\mathrm{K}_{2} \mathrm{P}_{\mathrm{CO}_{2}} \mathrm{P}_{\mathrm{H}_{2}}}\right]
$$

The reaction rate constants of $\mathrm{k}_{1}$ and $\mathrm{k}_{2}$ are strongly dependent on temperature and merely independent on the species concentration. The reaction rate constants (Eqs. (9) and (10)) are written as follows, in mol g cat ${ }^{-1} \mathrm{~s}^{-1}$ and $\mathrm{mol} \mathrm{Pa}^{-1} \mathrm{~g}_{\text {cat }}{ }^{-1} \mathrm{~s}^{-1}$ units, respectively [3].

$$
\mathrm{k}_{1}=1290 \exp \left[\frac{-102065}{\mathrm{RT}}\right]
$$

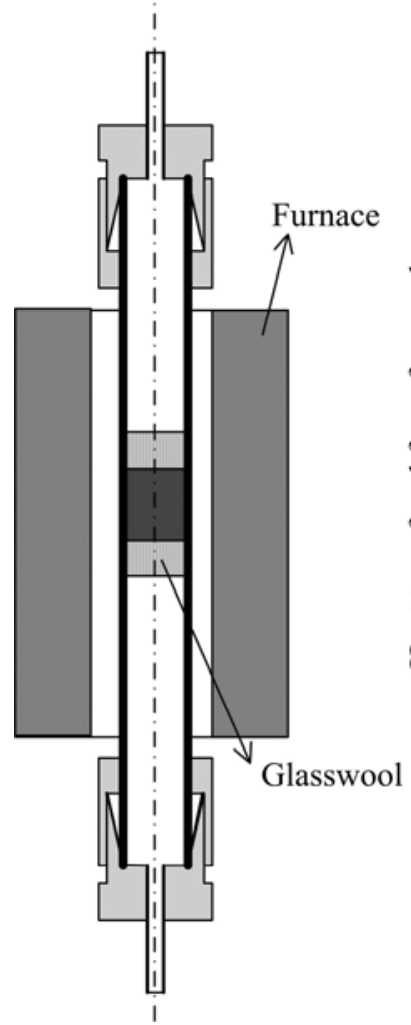

(a)

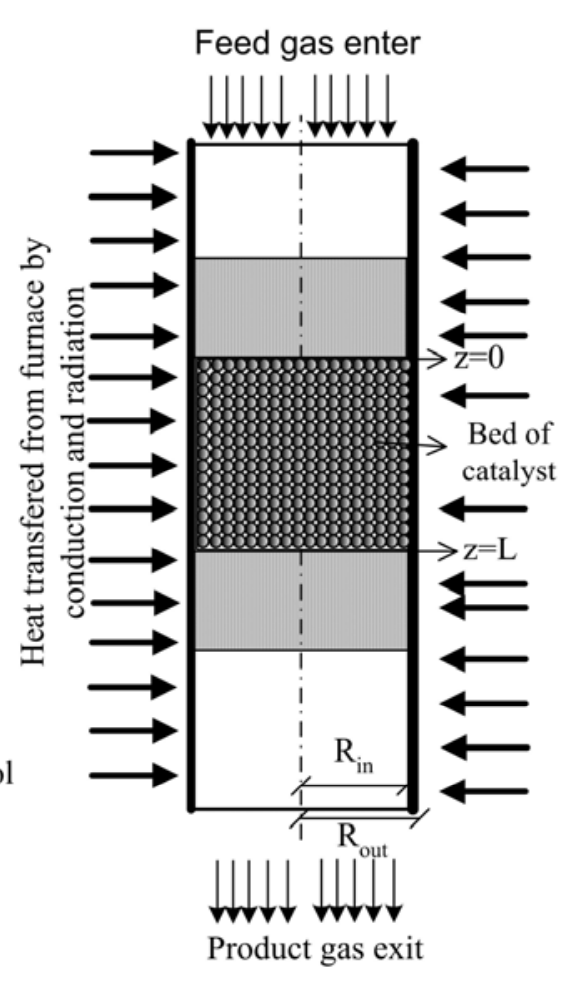

(b)

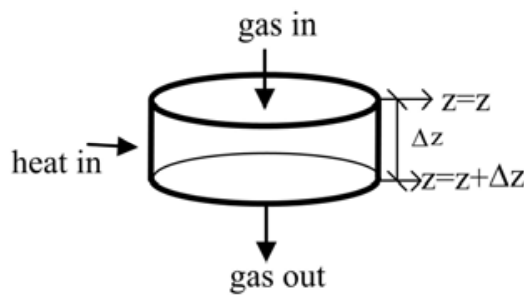

(c)

Figure 1. Schematic diagram of reactor configuration (a), element of reaction take place (b) and control volume for model building (c) 


$$
\mathrm{k}_{2}=1.856 \times 10^{-5} \exp \left[\frac{-73105}{\mathrm{RT}}\right]
$$

The adsorption equilibrium constants for $\mathrm{CH}_{4}$ and $\mathrm{CO}_{2}$ are $\mathrm{K}_{\mathrm{CH} 4}$ and $\mathrm{K}_{\mathrm{CO} 2}$, respectively, and described in Eqs. (11) and (12) expressed in $\mathrm{Pa}^{-1}$ unit [3].

$$
\begin{aligned}
& \mathrm{K}_{\mathrm{CH}_{4}}=2.63 \times 10^{3} \exp \left[\frac{40684}{\mathrm{RT}}\right] \\
& \mathrm{K}_{\mathrm{CO}_{2}}=2.64 \times 10^{3} \exp \left[\frac{37641}{\mathrm{RT}}\right]
\end{aligned}
$$

\section{Conservation of Energy}

An energy equation is also developed to account for axial thermal gradients for the fixed-bed configuration due to the strong endothermicity of reforming reaction. The heat from the furnace can be transferred to the catalytic reaction section through the reactor wall via conduction and radiation process. The heat is supplied to the reactor and is distributed along the axial bed of the catalyst. An energy balance for the reactor is developed in this work as shown in Equation (13) [7] .

$$
\frac{\mathrm{dT}}{\mathrm{dz}}=\frac{\mathrm{U}+\left[-\operatorname{rate}\left(\mathrm{CO}_{2}\right)\right]\left\lfloor-\Delta \mathrm{H}_{\mathrm{R}, \mathrm{T}_{1}}-\Delta \mathrm{H}_{\mathrm{R}, \mathrm{T}_{2}}\right\rfloor}{\mathrm{F}_{\mathrm{CO}_{2}, \mathrm{o}}\left[\sum \Theta_{\mathrm{i}} \mathrm{C}_{\mathrm{p}_{1}}+\left(\mathrm{X}_{1} \Delta \mathrm{C}_{\mathrm{p}_{1}}\right)+\left(\mathrm{X}_{2} \Delta \mathrm{C}_{\mathrm{p}_{2}}\right)\right]}
$$

where:

$$
\mathrm{U}=\frac{2 \pi \mathrm{Lk}_{\mathrm{q}}\left(\mathrm{T}_{\mathrm{f}}-\mathrm{T}\right)}{\ln \left(\frac{\mathrm{R}_{\text {out }}}{\mathrm{R}_{\text {in }}}\right)}+2 \pi \mathrm{R}_{\text {out }} \mathrm{L} \sigma\left(\mathrm{T}_{\mathrm{f}}{ }^{4}-\mathrm{T}^{4}\right)
$$

$\Delta \mathrm{H}_{\mathrm{R}, \mathrm{T}, 1}=\sum \mathrm{H}_{1,298}^{\mathrm{o}}+\int_{298}^{\mathrm{T}} \Delta \mathrm{C}_{\mathrm{p}, 1} \mathrm{dT}$

$$
\Delta \mathrm{H}_{\mathrm{R}, \mathrm{T}, 2}=\sum \mathrm{H}_{2,298}^{\mathrm{o}}+\int_{298}^{\mathrm{T}} \Delta \mathrm{C}_{\mathrm{p}, 2} \mathrm{dT}
$$

\section{Numerical Solution}

The set of ordinary differential equations come from mass balances of $\mathrm{CH}_{4}$ and $\mathrm{CO}_{2}$ of Equations (3) and (4), respectively, as well as energy balance of Equation (13) at steady state were solved by utilizing ODE23S toolbox from MATLAB 6 . The boundary conditions to be used for simulation are:

$$
\text { at } \mathrm{z}=0, \mathrm{x}_{\mathrm{CH}_{4}}=\mathrm{x}_{\mathrm{CO}_{2}}=0 ; \mathrm{T}=\mathrm{T}_{0}
$$

The value of parameters to be simulated mainly for the intrinsic kinetic data are obtained from the previous studies of Prabhu et al. over the $\mathrm{Rh} / \mathrm{Al}_{2} \mathrm{O}_{3}$ catalyst [3], while the reactor specification is obtained from the lab scale fixed- bed as tabulated in Table 1. The bulk density of the catalyst bed is calculated from its relation to both particle density and bed porosity $\left(r_{b}=r_{p}\left(1-e_{b}\right)\right)$ [7]. The catalyst bed height (L) is calculated from its relation to the catalyst weight (W), bulk density of catalyst $\left(\mathrm{r}_{\mathrm{b}}\right)$ and cross sectional area of bed $\left(\mathrm{A}_{\mathrm{t}}\right)$ by the correlation of $L=W /\left(A_{t} . r_{b}\right)$. Initially, the feed gases are introduced into the reactor with at 24 $\mathrm{mmol} / \mathrm{s}$ of $\mathrm{CH}_{4}, 24 \mathrm{mmol} / \mathrm{s}$ of $\mathrm{CO}_{2}$ and $27 \mathrm{mmol} / \mathrm{s}$ of $\mathrm{Ar}$ as the inert gas.

Table 1. Parameters value used for reactor simulation

\begin{tabular}{|c|c|c|}
\hline Parameters & Values & Unit \\
\hline $\mathrm{k}_{\mathrm{q}}$ & 0.15 at $973 \mathrm{~K}$ & $\mathrm{Jm}^{-1} \mathrm{~s}^{-1} \mathrm{~K}^{-1}$ \\
\hline $\mathrm{R}_{\text {in }}$ & 0.0045 & $\mathrm{~m}$ \\
\hline $\mathrm{R}_{\text {ou }}$ & 0.0055 & $\mathrm{~m}$ \\
\hline $\mathrm{e}_{\mathrm{b}}$ & 0.6 & - \\
\hline $\mathrm{r}_{\mathrm{p}}$ & $3.0 \times 10^{6}$ & $\mathrm{~g} \mathrm{~m}^{-3}$ \\
\hline $\mathrm{W}_{\text {cat }}$ & 0.5 & $\mathrm{~g}$ \\
\hline $\mathrm{s}$ & $5.67 \times 10^{-8}$ & $\mathrm{Wm}^{-2} \mathrm{~K}^{-4}$ \\
\hline $\mathrm{d}_{\mathrm{p}}$ & $0.326 \times 10^{-3}$ & $\mathrm{~m}$ \\
\hline $\mathrm{R}$ & 8.314 & $\mathrm{~Pa} \mathrm{~m}^{3} \mathrm{~mol}^{-1} \mathrm{~K}$ \\
\hline
\end{tabular}

The mathematical models in the form of ordinary differential equations are solved numerically and the computer codes are built in MATLAB. The simulator is used to simulate the performance profiles along the axial bed of catalyst in terms of: $\mathrm{CH}_{4}$ and $\mathrm{CO}_{2}$ conversion, $\mathrm{H}_{2}$ and $\mathrm{CO}$ yield, molar flow rate, mole fraction and reactor temperature as well as van't Hoff plot of CORM and RWGS reactions. The simulator can also be used to simulate the re- 
actor performances at different reaction temperatures and catalyst loading.

\section{Results and Discussion}

In this study, the performances of carbon dioxide reforming of methane over $\mathrm{Rh} / \mathrm{Al}_{2} \mathrm{O}_{3}$ catalyst were simulated in a lab scale fixed-bed reactor. The arrangement of the catalyst bed inside the reactor and its control volume to be used for model building is depicted in Figure 1. The kinetic parameters used in this simulation were obtained from the results conducted on the fixed-bed and membrane reactor by the previous researchers [3]. The mathematical models were developed using the mass and energy balances over the catalyst bed. The length of the reactor bed was calculated based on the catalyst weight loaded and the bed porosity $\left(\mathrm{r}_{\mathrm{b}}\right)$ as mentioned above.

\section{Reactor Performance Simulation at Single Temperature of $1073 \mathrm{~K}$}

The profiles of the predicted methane and carbon dioxide conversion along the axial catalyst bed at $1073 \mathrm{~K}$ are depicted in Figure 2. The values for both $\mathrm{CH}_{4}$ and $\mathrm{CO}_{2}$ conversions are in the low value of about $10 \%$ at the initial section of the reactor bed and increasing gradually along the axial bed of the catalyst thus achieved maximum at the end of the bed to about $90 \%$ and $80 \%$ of $\mathrm{CO}_{2}$ and $\mathrm{CH}_{4}$ conversions, respectively. The $\mathrm{CO}_{2}$ conversion is higher than $\mathrm{CH}_{4}$, indicating that more $\mathrm{CO}_{2}$ has reacted compared to $\mathrm{CH}_{4}$. It is corresponding to the fact that $\mathrm{CO}_{2}$ can react not only in the CORM reaction (Equation (1)) but also in the RWGS reaction (Equation (2)).

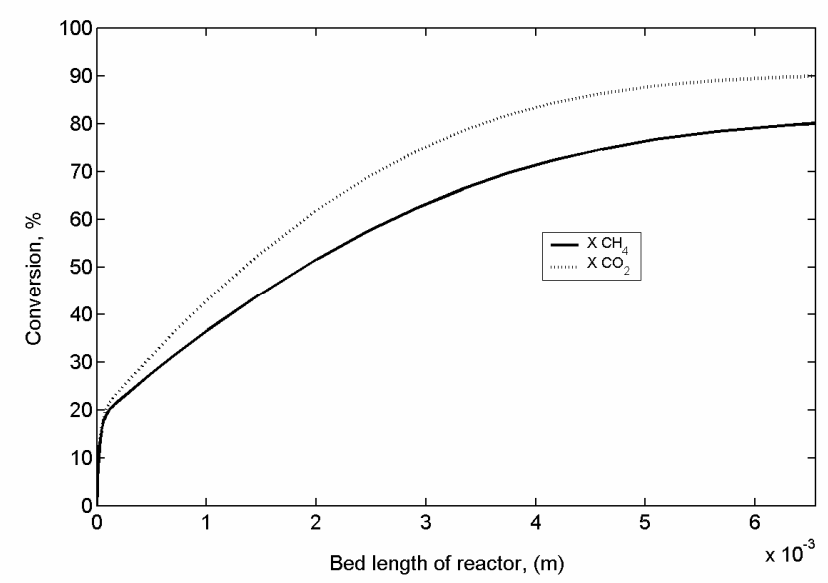

Figure 2. Profile of predicted methane and carbon dioxide conversion along the axial catalyst bed at $1073 \mathrm{~K}$ of reaction temperature

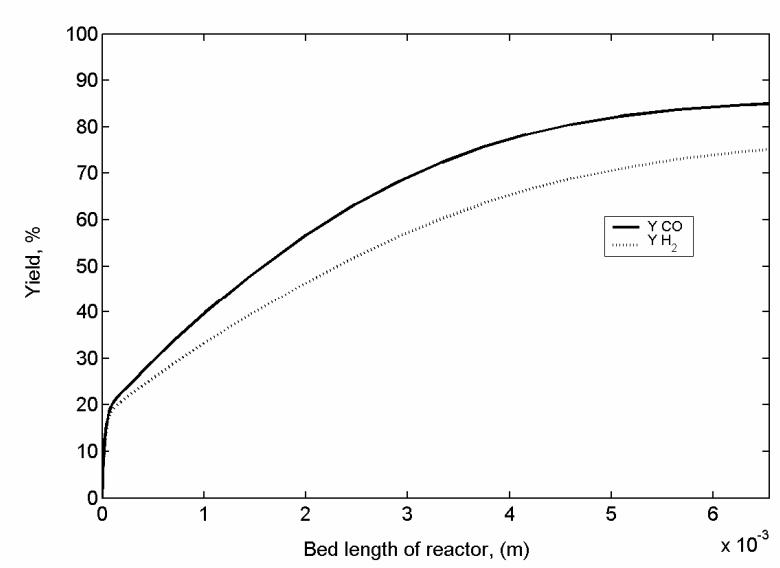

Figure 3. Profile of predicted $\mathrm{CO}$ and $\mathrm{H}_{2}$ yields along the axial catalyst bed at $1073 \mathrm{~K}$ of reaction temperature

Figure 3 describes the profiles of predicted both $\mathrm{CO}$ and $\mathrm{H}_{2}$ yields along the axial catalyst bed at the reaction temperature of $1073 \mathrm{~K}$. This figure shows that $\mathrm{CO}$ yield is higher than $\mathrm{H}_{2}$ yield. This can be attributed again to the RWGS reaction, in which hydrogen as one of the products from CORM reaction can react with $\mathrm{CO}_{2}$ reactant to produce $\mathrm{CO}$ and water, which led to a low $\mathrm{H}_{2} / \mathrm{CO}$ ratio. This phenomenon causes higher $\mathrm{CO}_{2}$ conversion than that of $\mathrm{CH}_{4}$ as depicted in Figure 2. The result in Figure 3 shows that the reforming reaction of $\mathrm{CO}_{2}$ and $\mathrm{CH}_{4}$ over $\mathrm{Rh} / \mathrm{Al}_{2} \mathrm{O}_{3}$ catalyst produces syngas of $\mathrm{CO}$ and $\mathrm{H}_{2}$ with the yields of $85 \%$ and $75 \%$, respectively, at the end section of the catalyst bed.

The profiles of the predicted molar flow rate and mole fraction of all species along the axial bed are depicted in Figures 4 and 5, respectively. From these figures, it can be shown that the molar flow rates of $\mathrm{CH}_{4}$ and $\mathrm{CO}_{2}$ decreased gradually along the axial bed as the two species are being consumed in both the CORM and RWGS reactions. The molar flow rate of $\mathrm{CO}_{2}$ is lower than that of $\mathrm{CH}_{4}$ due to the RWGS reaction. The molar flow rates of $\mathrm{CO}$ and $\mathrm{H}_{2}$ products increased along the axial bed of the catalyst due to the increasing $\mathrm{CH}_{4}$ and $\mathrm{CO}_{2}$ conversion, but some amount of water is also produced from the RWGS reaction. These phenomena are also revealed in the mole fraction profiles along the axial bed of the catalyst (Figure 5).

The mathematical model developed can also be applied to the design of a non-isothermal fixedbed reactor. The energy balance is coupled with the mass balance, rate laws and stoichiometry and must be solved simultaneously. The heat generated from the furnace to the reactor was assumed to be distributed uniformly along the axial bed of the catalyst. The homogeneous transfer along the axial bed of the catalyst and the endothermicity of the 


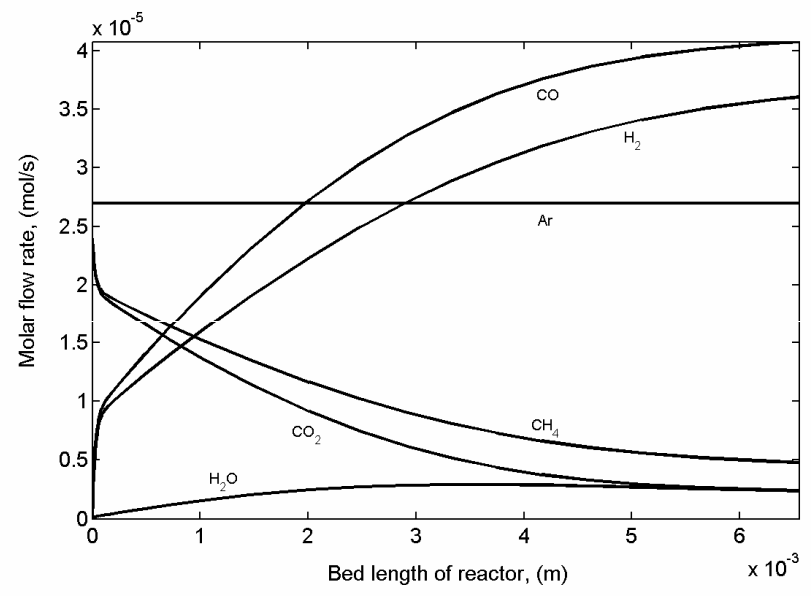

Figure 4. Profile of predicted molar flow rate of each species along the axial catalyst bed at 1073 $\mathrm{K}$ of reaction temperature

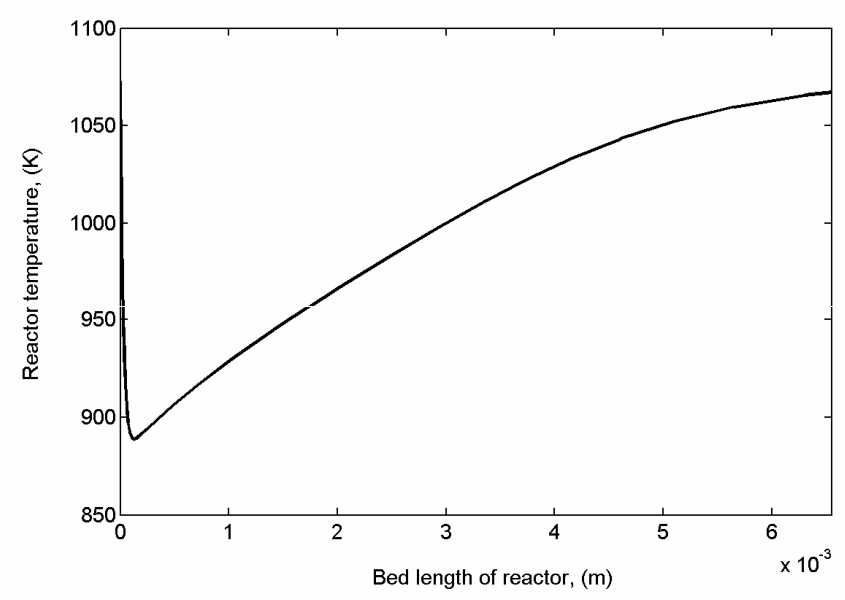

Figure 6. Profile of predicted internal reactor temperature along the axial catalyst bed at

reactions can cause the temperature to vary along the axial bed of the reactor. The profile of the predicted gas temperature along the axial bed of the catalyst is depicted in Figure 6. It is revealed that the temperature dropped drastically at the initial part of the reactor from the initial temperature of $1073 \mathrm{~K}$ to $890 \mathrm{~K}$ and then increased gradually to $1073 \mathrm{~K}$. This phenomenon is attributed to the large amount of heat required at the initial stage of the reactions due to the high endothermicity of both reactions. The rising temperature after a sudden drop along the axial bed of the catalyst is due to the heat supplied by the furnace along the reactor length during reaction, as depicted in Figure 1 , in which more heat is available at the end of the reactor bed.

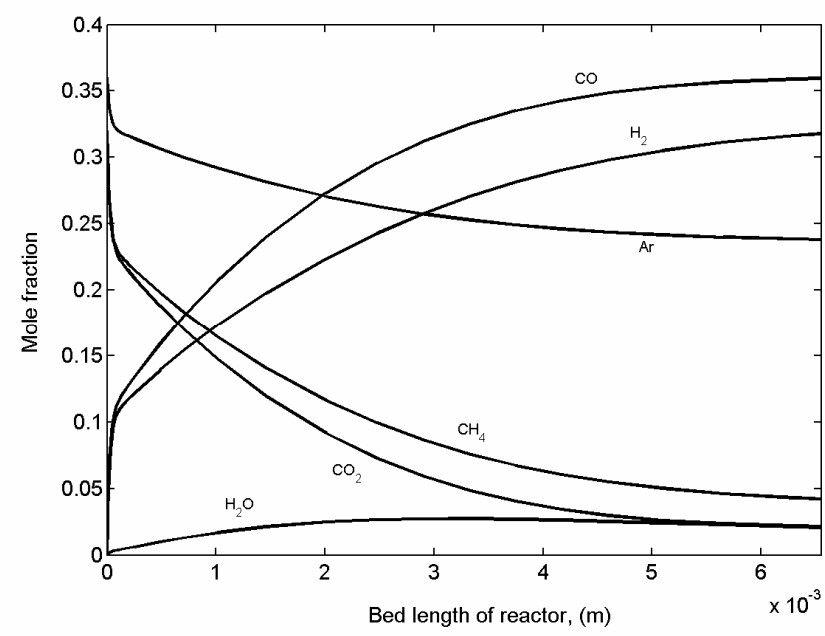

Figure 5. Profile of predicted mole fraction of each species along the axial catalyst bed at $1073 \mathrm{~K}$ of

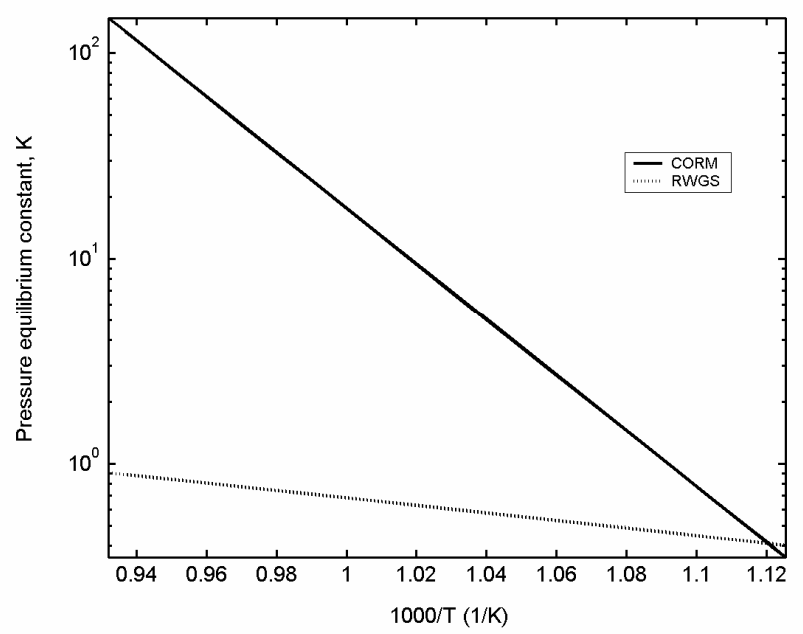

Figure 7. Profile of van't Hoff diagram for the adsorption-equilibrium constants for CORM and RWGS reactions

Figure 7 shows the calculated pressure equilibrium constants, $K$, in a van't Hoff plot for the carbon dioxide reforming of methane (CORM) and reverse water gas shift (RWGS) reaction at different temperatures along the axial bed. Thermodynamically, the dependence of $\mathrm{K}$ to temperature is according to van't Hoff equation (Equation (17)) [8]:

$$
\frac{\mathrm{d} \ln \mathrm{K}}{\mathrm{dT}}=\frac{\Delta \mathrm{H}^{\mathrm{o}}}{\mathrm{RT}^{2}}
$$

in which $\mathrm{K}$ can be calculated from its relation to the standard Gibbs-energy change as described in Equation (18). 


$$
\mathrm{K}=\exp \left(\frac{-\Delta \mathrm{G}^{0}}{\mathrm{RT}}\right)
$$

The values of the equilibrium constants, K, as depicted in Figure 7, are attributed to the endothermicity of both reactions. From this figure, it is shown that increasing temperature led to increasing $\mathrm{K}$ which is inline with the van't Hoff equation (Equation (17)) for endothermic reaction with positive $\Delta \mathrm{H}^{\circ}$.

\section{Influence the Various Reaction Tempera- tures $\left(700-1200{ }^{\circ} \mathrm{C}\right)$ to the Predicted Reactor Performances}

Influence of the different reaction temperature to the predicted reactor performances was also simulated in this work within the temperature range of $700-1200{ }^{\circ} \mathrm{C}(973-1423 \mathrm{~K})$. Figures 8(a) and (b) reveal the influence of various reaction temperatures to the predicted methane and carbon dioxide conversion along the axial bed of catalyst, respectively. Figures 9(a) and (b) pertain to the predicted profiles of $\mathrm{CO}$ and $\mathrm{H}_{2}$ yields with the reactor bed length, respectively. Low reactor temperature gives low $\mathrm{CH}_{4}$ and $\mathrm{CO}_{2}$ conversions. At the reactor temperature of $973 \mathrm{~K}$ both $\mathrm{CH}_{4}$ and $\mathrm{CO}$. 2 conversions are $46 \%$ and $62 \%$, respectively, at the end of the reactor bed. In addition, $\mathrm{CH}_{4}$ and $\mathrm{CO}_{2}$ conversions of $96 \%$ and $98 \%$, respectively, were achieved at reactor temperature of $1223 \mathrm{~K}$. Indeed, at higher reactor temperature of $1200{ }^{\circ} \mathrm{C}$ $(1423 \mathrm{~K})$, the $\mathrm{CH}_{4}$ and $\mathrm{CO}_{2}$ conversions were almost complete at $99 \%$ and close to $100 \%$, respec-
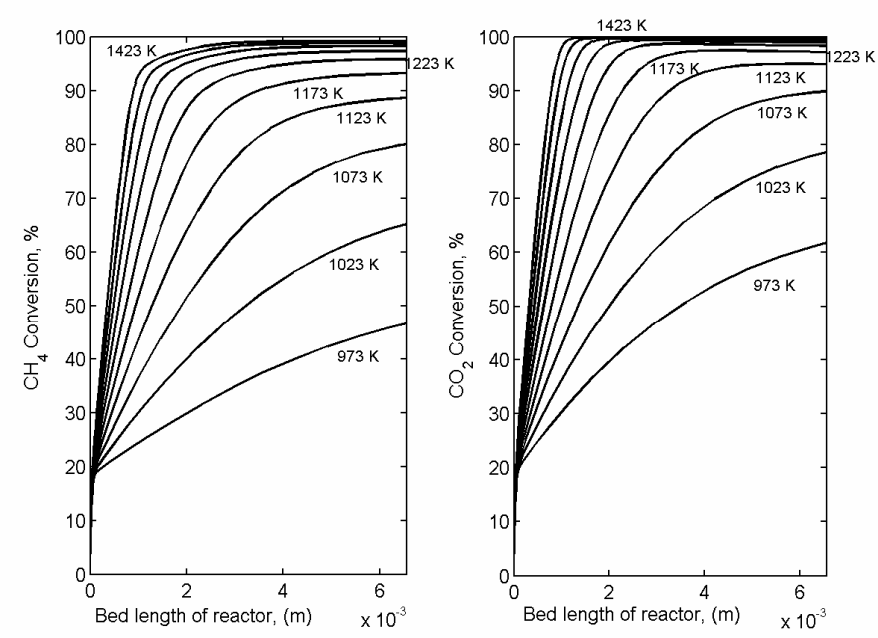

Figure 8. Effect of different reaction temperatures (700-1200 ${ }^{\circ} \mathrm{C}$ ) on $\mathrm{CH}_{4}$ (a) and $\mathrm{CO}_{2}$ (b) conversions along axial bed of catalyst tively. Unfortunately, a high temperature is needed to achieve complete conversions due to the fact that thermodynamically CORM and RWGS reactions are endothermic process. This phenomenon coincides with the formulation of van't Hoff of Equation (17), in which the equilibrium constant increases with temperature and finally leads to increasing reactant conversions. It is also in consistent with the predicted $\mathrm{CO}$ and $\mathrm{H}_{2}$ yields as shown in Figures 9 (a) and (b), respectively. The $\mathrm{CO}$ yield is close to $100 \%$ at temperature of $1200{ }^{\circ} \mathrm{C}(1423$ K), while $\mathrm{H}_{2}$ yield achieves $99 \%$. The profiles of $\mathrm{CH}_{4}$ and $\mathrm{CO}_{2}$ conversions, yields and selectivities of $\mathrm{H}_{2}$ and $\mathrm{CO}$, reactor temperature as well as $\mathrm{H}_{2} /$ $\mathrm{CO}$ ratio were more uniform along the axial bed of the catalyst at higher reaction temperature.

The profile of the predicted reactor temperature with the bed length at various reaction temperatures is depicted in Figure 10. It is shown that increasing reaction temperatures lead to the uniformity of temperature profile along the axial bed that finally results in a more efficient usage of the reactor. It is highly desired that the $\mathrm{H}_{2} / \mathrm{CO}$ ratio approached unity for the utilization of the synthesis gas in the Fischer-Tropsch reaction [9]. The simulation of the $\mathrm{H}_{2} / \mathrm{CO}$ ratio along the axial bed of the catalyst at various temperatures is depicted in Figure 11. From this figure, it is shown that at low reaction temperatures, the $\mathrm{H}_{2} / \mathrm{CO}$ ratio dropped drastically and gradually increased along the axial bed of the catalyst. For example, at $973 \mathrm{~K}$, the $\mathrm{H}_{2} /$ $\mathrm{CO}$ ratio dropped drastically to 0.70 at the centre of the reactor bed length. Different behaviour is
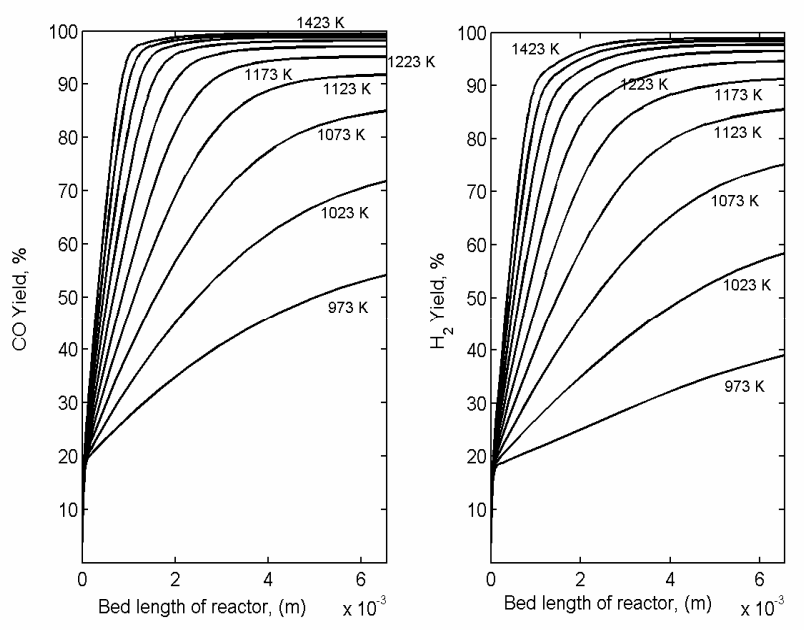

Figure 9 Effect of different reaction temperatures $\left(700-1200{ }^{\circ} \mathrm{C}\right)$ on the predicted $\mathrm{CO}$ (a) and $\mathrm{H}_{2}$ (b) yields along axial bed of catalyst 
shown at higher temperature (above $1223 \mathrm{~K}$ ) for the predicted $\mathrm{H}_{2} / \mathrm{CO}$ ratio. At higher temperatures, $\mathrm{H}_{2} / \mathrm{CO}$ ratio dropped initially but increased rapidly to achieve uniform $\mathrm{H}_{2} / \mathrm{CO}$ ratio along the axial bed of the catalyst. It is shown that at temperatures above $1423 \mathrm{~K}$, the $\mathrm{H}_{2} / \mathrm{CO}$ ratio increases to about 0.995 . This phenomenon is attributed to the effect of temperature distribution to the $\mathrm{H}_{2} / \mathrm{CO}$ ratio along the axial bed of the catalyst. The RWGS reaction is more favourable at low temperature. It is consistent with the study that CORM reaction can proceed above $640{ }^{\circ} \mathrm{C}$ accompanied by methane dissociation reaction. Based on the Gibbs free energy consideration both RWGS and Boudouard reactions could not occur at reaction temperature above $820{ }^{\circ} \mathrm{C}$ [10], as revealed by Equation (18) [8]. Increasing the reaction temperature to above $820{ }^{\circ} \mathrm{C}$ resulted in a higher $\mathrm{H}_{2} / \mathrm{CO}$ ratio due to the suppression of $\mathrm{H}_{2}$ reaction with $\mathrm{CO}_{2}$ in the RWGS reaction as shown in Figure 11.

\section{Conclusions}

A one-dimensional mathematical model for the fixed bed reactor was developed to simulate the performance of $\mathrm{CO}_{2}$ reforming of methane to synthesis gas over $\mathrm{Rh} / \mathrm{Al}_{2} \mathrm{O}_{3}$ catalyst system. In this modelling and simulation, the profiles of reactor performance can be simulated along the axial bed of catalyst in terms of $\mathrm{CH}_{4}$ and $\mathrm{CO}_{2}$ conversions, $\mathrm{CO}$ and $\mathrm{H}_{2}$ yields, molar flow rate and mole fraction of all species, reactor temperature and also equilibrium constants. In addition, the effect of

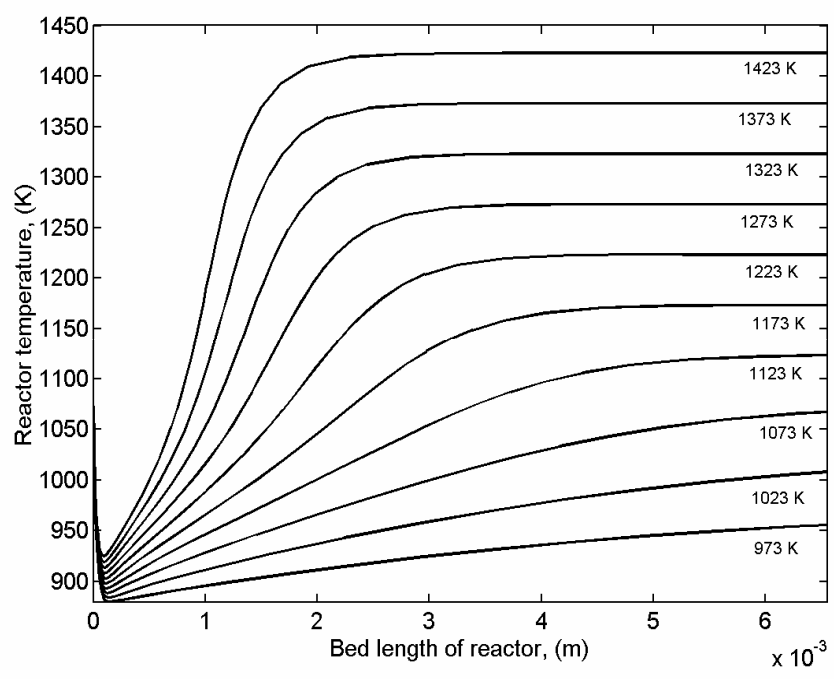

Figure 10. Predicted temperature profile along axial bed of catalyst at different reaction temperatures $\left(700-1200{ }^{\circ} \mathrm{C}\right)$ different reactor temperature on the $\mathrm{CH}_{4}$ and $\mathrm{CO}_{2}$ conversion along the axial bed of the catalyst was also simulated as well as its influence on the $\mathrm{CO}$ and $\mathrm{H}_{2}$ yields. It is also predicted that the axial gradients of temperature and conversion were negligible at high reaction temperature. The $\mathrm{H}_{2} / \mathrm{CO}$ ratio close to unity was also achieved at high reaction temperature. In future, the models can be modified to consider the effects of pressure drop or fluid dynamic, the effectiveness factor as well as coking rate on the reactor performances.

\section{REFERENCES}

1. Suhartanto, T., York, A.P.E., Hanif, A., AlMegren, H. and Green, M.L.H., 2001, Potential Utilisation of Indonesia's Natuna Natural Gas Field via Methane Dry Reforming to Synthesis Gas, Catal. Lett., 71(1-2): 49-54

2. Larentis, A.L., de Resende, N.S., Salim, V.M.M. and Pinto, J.C., 2001, Modelling and Optimization of The Combined Carbon Dioxide Reforming and Partial Oxidation of Natural Gas, Appl. Catal. A: Gen., 215: 211224

3. Prabhu, A.K., Liu, A., Lovell, L.G. and Oyama, S.T., 2000, Modelling of The Methane reforming Reaction in Hydrogen Selective Membrane Reactors, J. Membr. Sci., 177: 83-95

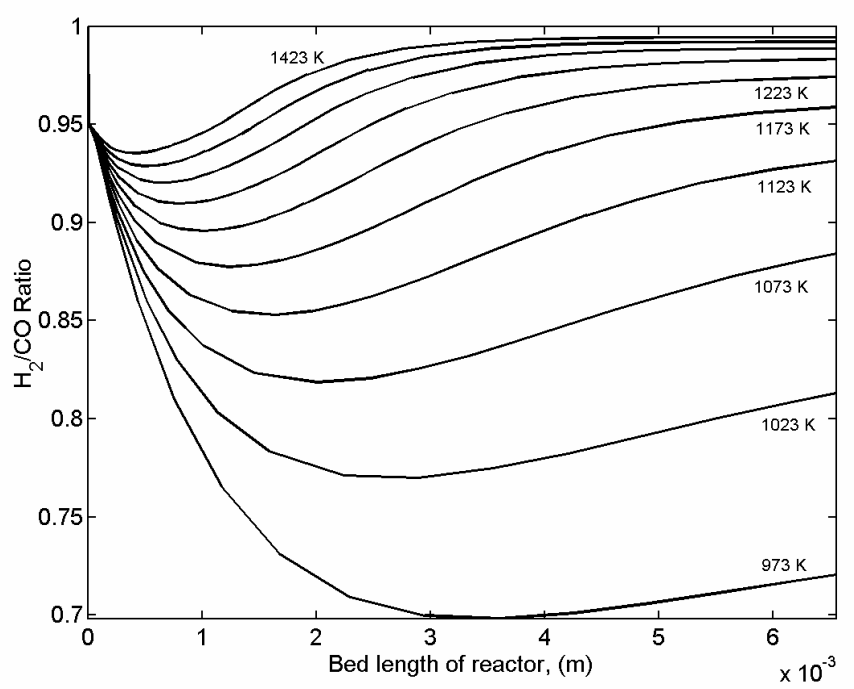

Figure 11. Predicted $\mathrm{H}_{2} / \mathrm{CO}$ ratio along axial bed of catalyst effect at different reaction temperatures $\left(700-1200{ }^{\circ} \mathrm{C}\right)$ 
4. Froment, G.F., 2000, Production of Synthesis Gas by Steam- and $\mathrm{CO}_{2}$-Reforming of Natural Gas, J. Mol. Catal. A: Chem., 163: 147156

5. Mohammadzadeh, J.S.S. and Zamaniyan, A., 2002, Catalyst Shape as a Design Parameter - Optimum Shape for Methane-Steam Reforming Catalyst, Trans. Inst. Chem. Eng. Part A, 80: 383-391

6. Slamet and Harjito, E., 2001, Kinetic Studies of $\mathrm{CH}_{4} / \mathrm{CO}_{2}$ Reforming Reaction over $\mathrm{Ni} /$ $\mathrm{La}_{2} \mathrm{O}_{3}$ Catalyst Using Integral Reactor, Pros. Sem. Nas. Rekayasa Kimia dan Proses 2001, E-4.1-E-4.7 (in Indonesian)

7. Fogler, H.S., 1999, Elements of Chemical Reaction Engineering, Prentice-Hall International Inc., Toronto, Canada.

8. Smith, J. M., Van Ness, H. C. and Abbott, M. M., 2001, Introduction to Chemical Engineering Thermodynamics, $6^{\text {th }}$ Ed., McGraw-Hill Inc., Singapore

9. Krylov, O.V., Mamedov, A.Kh. and Mirzabekova, S.R., 1998, Interaction of Carbon Dioxide with Methane on the Oxide Catalysts, Catal. Today, 42: 211-215

10. Wang, S., Lu, G.Q.M. and Millar, G.J., 1996, Carbon Dioxide Reforming of Methane to Produce Synthesis Gas over MetalSupported Catalysts: State of the Art, Energy and Fuel, 10: 896-904

\section{Nomenclatures}

$\mathrm{A}_{\mathrm{t}} \quad$ cross sectional area of catalyst bed, $\mathrm{m}^{2}$

$\mathrm{C}_{\mathrm{pi}} \quad$ heat capacity of species $\mathrm{i}$, $\mathrm{J} \mathrm{mol}^{-1} \mathrm{~K}^{-1}$

$\mathrm{F}^{\circ} \mathrm{CO} 2$ initial molar flow rate of $\mathrm{CO}_{2}$, $\mathrm{mol} \mathrm{s}^{-1}$

$\mathrm{K}_{1} \quad$ equilibrium constant for CORM reaction

$\mathrm{K}_{2}$ equilibrium constant for RWGS reaction

$\mathrm{k}_{1} \quad$ rate constant for CORM reaction, mol g cat ${ }^{-1} \mathrm{~s}^{-1}$

$\mathrm{k}_{2} \quad$ rate constant for RWGS reaction, mol atm $^{-1}$ g cat $^{-1} \mathrm{~s}^{-1}$

\begin{tabular}{|c|c|}
\hline $\mathrm{k}_{\mathrm{q}}$ & $\begin{array}{l}\text { thermal conductivity of quartz, } \mathrm{J} \mathrm{m}^{-} \\
{ }^{1} \mathrm{~s}^{-1} \mathrm{~K}^{-1}\end{array}$ \\
\hline $\mathrm{L}$ & bed length of reactor, $\mathrm{m}$ \\
\hline $\mathrm{P}_{\mathrm{i}}$ & partial pressure of species $\mathrm{i}, \mathrm{Pa}$ \\
\hline$r_{1}$ & $\begin{array}{l}\text { net intrinsic reaction rate of CORM, } \\
\text { mol g cat } \text { c }^{-1} \mathrm{~s}^{-1}\end{array}$ \\
\hline $\mathrm{r}_{2}$ & 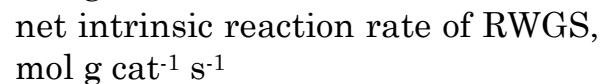 \\
\hline $\mathrm{R}$ & gas constant, $\mathrm{Pa} \mathrm{m}^{3} \mathrm{~mol}^{-1} \mathrm{~K}^{-1}$ \\
\hline $\mathrm{R}_{\text {out }}$ & outer radius of reactor, $\mathrm{m}$ \\
\hline $\mathrm{R}_{\text {in }}$ & inner radius of reactor, $\mathrm{m}$ \\
\hline $\mathrm{R}_{\mathrm{CH} 4}$ & $\begin{array}{l}\text { rate of } \mathrm{CH}_{4} \text { disappearance, mol g } \\
\text { cat }^{-1} \mathrm{~s}^{-1}\end{array}$ \\
\hline $\mathrm{R}_{\mathrm{CO} 2}$ & $\begin{array}{l}\text { rate of } \mathrm{CO}_{2} \text { disappearance, mol } \mathrm{g} \\
\text { cat-1 }^{-1} \mathrm{~s}^{-1}\end{array}$ \\
\hline $\mathrm{T}$ & reactor temperature, $\mathrm{K}$ \\
\hline $\mathrm{T}_{\mathrm{f}}$ & furnace temperature, $\mathrm{K}$ \\
\hline $\mathrm{U}$ & heat generated by furnace, $\mathrm{J} \mathrm{s}^{-1}$ \\
\hline $\mathrm{W}$ & weight of catalyst, g cat. \\
\hline $\mathrm{x}_{\mathrm{CH} 4}$ & $\mathrm{CH}_{4}$ conversion, $\%$ \\
\hline $\mathrm{x}_{\mathrm{CO} 2}$ & $\mathrm{CO}_{2}$ conversion, $\%$ \\
\hline
\end{tabular}

$\mathrm{X}_{1}, \mathrm{X}_{2} \quad$ conversion of $\mathrm{CO}_{2}$ from reaction (1) and (2), respectively

$\Omega \quad$ cross sectional area of reactor, $\mathrm{m}^{2}$

$\rho_{b} \quad$ bulk density of the bed of catalyst, $g$ cat $m^{-3}$ reactor

$\rho_{\mathrm{p}} \quad$ density of the catalyst particle, $\mathrm{g} \mathrm{m}^{-}$ ${ }^{3}$ cat.

nCH4 effectiveness factor for CORM reaction

nCO2 effectiveness factor for RWGS reaction

$\Delta \mathrm{H} \quad$ heat of reaction, $\mathrm{J} \mathrm{mol}^{-1}$

$\Delta \mathrm{H}_{\mathrm{R}, \mathrm{T} 1} \quad$ heat of reaction for reaction (1), $\mathrm{J}$ $\mathrm{mol}^{-1}$

$\Delta \mathrm{H}_{\mathrm{R}, \mathrm{T} 2} \quad$ heat of reaction for reaction (2), $\mathrm{J}$ $\mathrm{mol}^{-1}$

$\Theta_{\mathrm{i}} \quad$ stoichiometric ratio of species $\mathrm{i}$

$\Delta \mathrm{C}_{\mathrm{p} 1}, \mathrm{C}_{\mathrm{p} 2}$ sum of heat capacities for reaction (1) and (2), respectively, $\mathrm{J} \mathrm{mol}^{-1} \mathrm{~K}^{-1}$

$\Delta \mathrm{G} \quad$ Gibbs energy of reaction, $\mathrm{J} \mathrm{mol}^{-1}$

o Stefan-Boltzmann constant, $\mathrm{W} \mathrm{m} \mathrm{m}^{-2}$ $\mathrm{K}^{-4}$ 